\title{
Vibrational Spectroscopic and Computational Analysis of 5-chloro-2-hydroxy Acetophenone
}

\author{
Palani Murugan, S. Jeyavijayan,Naidu Dhanpal Jayram, K. Viswanathan
}

\begin{abstract}
Fourier Transfer infrared and Raman spectra in the range of 4000-400 $\mathrm{cm}^{-1}$ and $3500-50 \mathrm{~cm}^{-1}$ were recorded to study the vibrational spectra of 5-chloro-2-hydroxyacetophenone (CHAP). Using density functional theory (DFT/B3LYP) with $6-31+G(d, p)$ and 6-311++G(d,p) basis sets the various geometrical parameters such as Raman activities, infrared intensities and optimum frequencies were calculated. The HOMO-LUMO energy gap has been computed which confirms the charge transfer of the molecular system. Mulliken's atomic charges associated with each atom and thermodynamic parameters have also been reported with the same level of DFT.
\end{abstract}

Keywords:5-chloro-2-hydroxy FT-Raman; DFT.

acetophenone;

FTIR;

\section{INTRODUCTION}

The biological and physicochemical properties of acetophenone compounds have shown interesting behaviour in nature through diverse synthesis procedures [1,2]. Recent studies in antibacterial activity of 20 acetophenones using electronic and topological indices have shown interesting structural characteristics [3]. Among them, hydroxy acetophenone is employed as building block for the synthesis of rubbers, plastics, agrochemicals flavor, fragrances and pharmaceuticals. Due to the versatile behaviors of acetophenone, Seth et al. investigated the crystallograpic and spectroscopic studies of ortho-hydroxy acetophenones [4]. Recently, many researchers have studied the computational and vibrational spectra of hydroxyacetophenone derivatives $[5,6]$. Consideration of these factors leads to study the detailed spectral investigation of 5-chloro-2-hydroxyacetophenone (CHAP).

\section{EXPERIMENTAL}

The fine polycrystalline sample of CHAP was purchased from commercial sources with a stated purity of $99 \%$ and they were used as such without further purification. The Fourier transform infrared spectra was recorded in the region

Revised Manuscript Received on December 20, 2019.

* Correspondence Author

Palani Murugan, Department of Physics, Dr. B.R. Ambedkar Institute of Technology, Port Blair-744103, Andaman \& Nicobar Islands, India Email : palanimuruganviji@gmail.com

S. Jeyavijayan*, Department of Physics , Kalasalingam Academy of Research and Education, Krishnankoil-626 126, Tamil Nadu, India Email : sjeyavijayan@gmail.com

Naidu Dhanpal Jayram, Department of Physics, Kalasalingam Academy of Research and Education, Krishnankoil-626 126,Tamil Nadu, India

Email : revz.vijay@gmail.com

K. Viswanathan, Department of Physics, Kalasalingam Academy of Research and Education, Krishnankoil-626 126, Tamil Nadu, India Email : kvnooty@gmail.com
4000-400 $\mathrm{cm}^{-1}$, using Perkin Elmer FTIR spectrometer equipped with an MCT detector, a $\mathrm{KBr}$ beam splitter and globar source. The FT-Raman spectrum of CHAP was recorded on a computer interfaced BRUKER RFS-66V model interferometer in the Stokes region $4000-50 \mathrm{~cm}^{-1}$ using Nd: YAG laser operating at $200 \mathrm{~mW}$ power continuously with $1064 \mathrm{~nm}$ excitation.

\section{COMPUTATION AND SIMULATION}

In the quantum chemical calculations, DFT has proved to be very useful in treating electronic structure of molecules. The DFT calculations were carried out for CHAP with GAUSSIAN 09W program package [7] using the Becke's three parameter hybrids functional combined with the Lee-Yang-Parr correlation (B3LYP) functional [8,9] with standard $6-31+\mathrm{G}(\mathrm{d}, \mathrm{p})$ and $6-311++\mathrm{G}(\mathrm{d}, \mathrm{p})$ basis sets. The total energy distribution (TED) associated with each vibration is calculated by the MOLVIB program (version V7.0-G77) written by Sundius [10]. The HOMO-LUMO and Mulliken charge analyses have been computed with same level of calculations to elucidate information regarding charge transfer within the molecule.

\section{RESULT AND DISCUSSION}

\section{A. Molecular Geometry}

Fig. 1 shows the optimized molecular structure of CHAP. DFT structure optimization with standard $6-31+G(d, p)$ and 6-311++G(d,p) basis sets gives global minimum energy value as -919.577287 and -919.709992 Hartrees, respectively. The optimized geometrical parameters of CHAP calculated by using the above methods in comparison with the experimental data [11] are presented in the Table I. The thermodynamic characteristics like zero point vibrational energy (ZPVE), dipole moment, heat capacity and entropy were computed at same level of calculations for CHAP as presented in Table II. In this study, the dipolemoment molecule of CHAP is found to be 3.8702 and 3.8537 Debye, for lower and higher basis sets, respectively. All the thermodynamic data provide helpful information for the further study on the CHAP. 


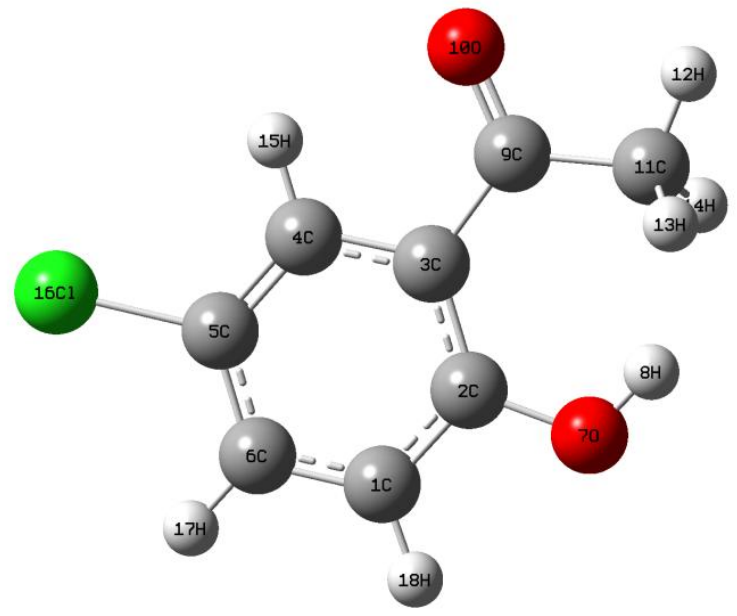

Figure 1. Molecular structure of 5-chloro-2-hydroxy acetophenone

\section{B. Vibrational Spectral Analysis}

The molecule under investigation contains 18 atoms and hence it has 48 modes $(3 \mathrm{~N}-6)$ of vibrations. The geometry of the molecule CHAP is considered to possess $\mathrm{C}_{1}$ point group symmetry. The IR and Raman peaks are active for all the vibrations of molecule. The observed FTIR and FT-Raman spectra of CHAP are presented in Fig. 2. The detailed vibrational assignment of fundamental modes of CHAP along with the calculated IR intensities, Raman activities, and normal mode descriptions (characterised by TED) are reported in Table III.
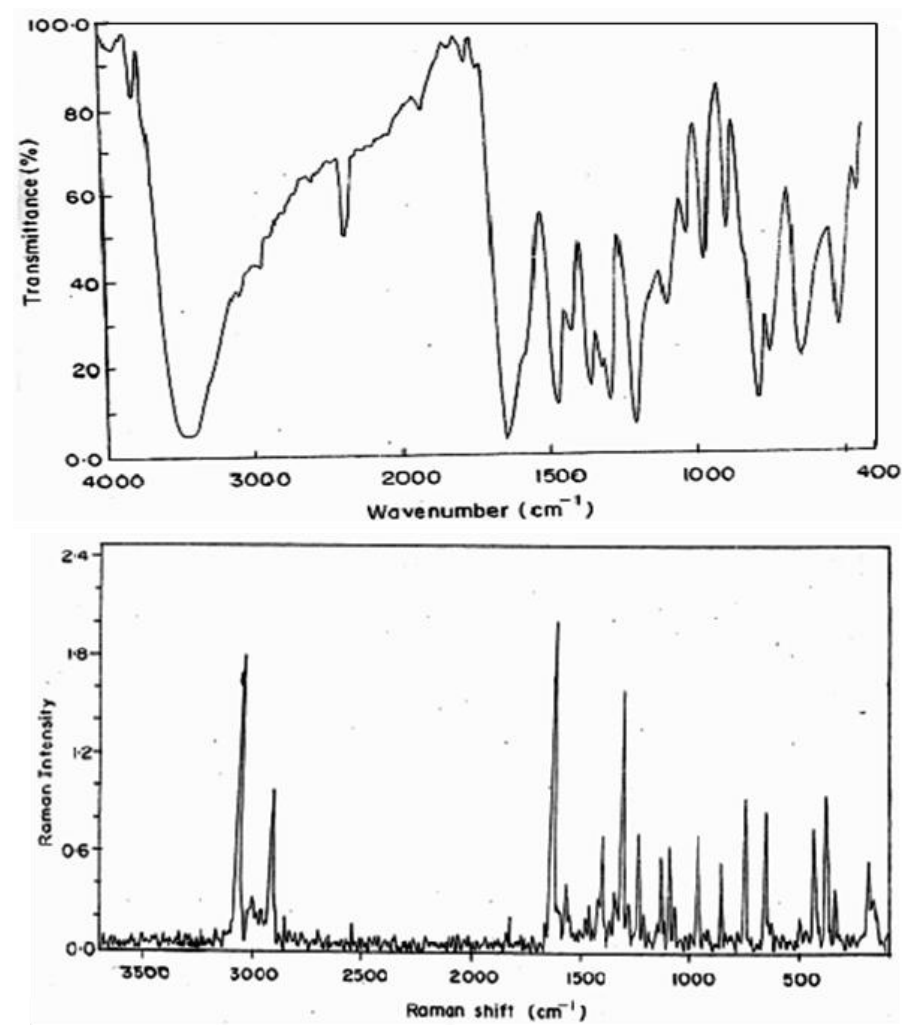

Figure 2. FTIR and FT-Raman spectra of 5-chloro-2-hydroxy acetophenone

Anharmonicity and the general tendency of the quantum mechanical methods show variation in the corresponding experimental quantities and calculated wavenumbers. This

results into overestimate the force constants at the equilibrium geometry. Therefore, in order to improve the calculated values in agreement with the experimental ones, calculated harmonic frequencies are scale down. Using scale factor [12] of 0.96 for B3LYP method, an improved agreement between the computed and experimental frequencies is obtained and listed in Table III.

Table I.Experimental (XRD) and optimized geometrical parameters of 5-chloro-2-hydroxy acetophenone

\begin{tabular}{|c|c|c|c|}
\hline $\begin{array}{l}\text { Bond length } \\
(\AA)\end{array}$ & $\begin{array}{c}\text { B3LYP/ } \\
6-31+G(d, p)\end{array}$ & $6-311++G(d, p)$ & $\operatorname{Expt}^{11}$ \\
\hline $\mathrm{C} 1-\mathrm{C} 2$ & 1.405 & 1.402 & 1.39 \\
\hline C1-C6 & 1.391 & 1.387 & 1.377 \\
\hline $\mathrm{C} 2-\mathrm{C} 3$ & 1.417 & 1.414 & 1.419 \\
\hline $\mathrm{C} 2-\mathrm{O} 7$ & 1.391 & 1.391 & 1.352 \\
\hline $\mathrm{C} 3-\mathrm{C} 4$ & 1.418 & 1.416 & 1.405 \\
\hline C3-C9 & 1.495 & 1.494 & 1.477 \\
\hline C4-C5 & 1.381 & 1.377 & 1.376 \\
\hline $\mathrm{C} 5-\mathrm{C} 6$ & 1.4 & 1.397 & 1.392 \\
\hline C5-Cl16 & 1.825 & 1.827 & 1.75 \\
\hline C9-O10 & 1.25 & 1.247 & 1.237 \\
\hline C9-C11 & 1.518 & 1.516 & 1.5 \\
\hline \multicolumn{4}{|l|}{$\begin{array}{l}\text { Bond angle } \\
\left({ }^{\circ}\right)\end{array}$} \\
\hline C2-C1-C6 & 120.84 & 120.86 & 120.6 \\
\hline $\mathrm{C} 1-\mathrm{C} 2-\mathrm{C} 3$ & 120.6 & 120.57 & 120 \\
\hline $\mathrm{C} 1-\mathrm{C} 2-\mathrm{O} 7$ & 113.24 & 113.31 & 117.9 \\
\hline $\mathrm{C} 3-\mathrm{C} 2-\mathrm{O} 7$ & 126.16 & 126.12 & 122.1 \\
\hline $\mathrm{C} 2-\mathrm{C} 3-\mathrm{C} 4$ & 117.56 & 117.58 & 118.7 \\
\hline C2-C3-C9 & 126.92 & 126.87 & 119.8 \\
\hline C4-C3-C9 & 115.52 & 115.55 & 121.5 \\
\hline C3-C4-C5 & 120.88 & 120.79 & 119.8 \\
\hline C4-C5-C6 & 121.42 & 121.53 & 121.5 \\
\hline C4-C5-Cl16 & 119.64 & 119.58 & 118.9 \\
\hline C6-C5-Cl16 & 118.95 & 118.89 & 119.6 \\
\hline C1-C6-C5 & 118.71 & 118.67 & 119.4 \\
\hline C3-C9-O10 & 119.84 & 119.71 & 120.3 \\
\hline C3-C9-C11 & 122.18 & 122.2 & 120 \\
\hline O10-C9-C11 & 117.98 & 118.08 & 119.7 \\
\hline
\end{tabular}

Table II. Theoretically computed thermodynamic parameters of 5-chloro-2-hydroxy acetophenone

\begin{tabular}{ccc}
\hline Parameter & $\begin{array}{c}\mathrm{B} 3 \mathrm{LYP} / 6-3 \\
1+\mathrm{G}(\mathrm{d}, \mathrm{p})\end{array}$ & $\begin{array}{c}\mathrm{B} 3 \mathrm{LYP} / 6-31 \\
1++\mathrm{G}(\mathrm{d}, \mathrm{p})\end{array}$ \\
\hline $\begin{array}{c}\text { Zeropoint vibrational energy }\left(\mathrm{kcal} \mathrm{mol}^{-1}\right) \\
\text { Thermal energy }\left(\mathrm{kcal} \mathrm{mol}^{-1}\right)\end{array}$ & 89.4635 & 82.5431 \\
Heat capacity, $\mathrm{C}_{\mathrm{v}}\left(\mathrm{calmol}^{-1} \mathrm{~K}^{-1}\right)$ & 37.579 & 88.544 \\
Entropy (cal mol $\left.{ }^{-1} \mathrm{~K}^{-1}\right)$ & & \\
Total & 102.153 & 97.020 \\
\hline
\end{tabular}




\begin{tabular}{|c|c|c|c|c|c|}
\hline Translational & 41.300 & 41.300 & $\mu_{y}$ & 2.7931 & 2.7667 \\
\hline Rotational & 30.957 & 30.949 & $\mu_{z}$ & 0.0014 & 0.0011 \\
\hline Vibrational & 29.896 & 24.771 & $\mu_{\text {total }}$ & 3.8702 & 3.8537 \\
\hline
\end{tabular}

Dipole moment (Debye)

$\begin{array}{lll}\mu_{x} & -2.6790 & -2.6826\end{array}$

Table III. FTIR, Raman and calculated (unscaled and scaled) vibrational frequencies $\left(\mathrm{cm}^{-1}\right)$, IR intensity $\left(\mathrm{km} \mathrm{mol}^{-1}\right)$, Raman activity $\left(\AA^{4} \mathrm{amu}^{-1}\right)$, and vibrational assignments of 5-chloro-2-hydroxy acetophenone

\begin{tabular}{|c|c|c|c|c|c|c|c|c|c|c|c|}
\hline \multirow{3}{*}{ Sl.No } & \multirow{2}{*}{\multicolumn{2}{|c|}{$\begin{array}{l}\text { Experimental } \\
\text { frequencies }\left(\mathrm{cm}^{-1}\right)\end{array}$}} & \multicolumn{8}{|c|}{ Calculated frequencies $\left(\mathrm{cm}^{-1}\right)$} & \multirow{3}{*}{$\begin{array}{l}\text { Assignment } \\
\text { with TED } \\
(\%)\end{array}$} \\
\hline & & & \multicolumn{4}{|c|}{ B3LYP/6-31+G(d,p) } & \multicolumn{4}{|c|}{ B3LYP/6-311++G(d,p) } & \\
\hline & FTIR & FT-Raman & $\begin{array}{l}\text { Un } \\
\text { Scaled }\end{array}$ & Scaled & $\begin{array}{c}\text { IR } \\
\text { intensity }\end{array}$ & $\begin{array}{l}\text { Raman } \\
\text { activity }\end{array}$ & $\begin{array}{l}\text { Un } \\
\text { Scaled }\end{array}$ & Scaled & $\begin{array}{c}\text { IR } \\
\text { intensity }\end{array}$ & $\begin{array}{l}\text { Raman } \\
\text { activity }\end{array}$ & \\
\hline 1 & $3544(\mathrm{~s})$ & - & 3731 & 3582 & 142.15 & 60.08 & 3748 & 3598 & 171.85 & 99.39 & $v \mathrm{OH}(98)$ \\
\hline 2 & $3080(\mathrm{vw})$ & - & 3248 & 3118 & 4.28 & 39.48 & 3218 & 3089 & 8.33 & 46.74 & $v \mathrm{CH}(96)$ \\
\hline 3 & - & $3075(\mathrm{vs})$ & 3246 & 3117 & 2.48 & 140.22 & 3216 & 3088 & 1.13 & 161.55 & vCH (97) \\
\hline 4 & - & 3011(w) & 3231 & 3102 & 1.47 & 52.92 & 3200 & 3072 & 1.19 & 64.13 & vCH (95) \\
\hline 5 & 2927(w) & $2927(\mathrm{vw})$ & 3160 & 3034 & 8.95 & 79.90 & 3133 & 3008 & 5.00 & 110.34 & $\mathrm{CH}_{3}$ ips (92) \\
\hline 6 & - & $2862(\mathrm{~s})$ & 3090 & 2966 & 10.09 & 54.61 & 3064 & 2941 & 5.14 & 40.00 & $\mathrm{CH}_{3}$ ss (94) \\
\hline 7 & 2913(s) & - & 3021 & 2900 & 9.89 & 125.91 & 2997 & 2877 & 5.85 & 151.00 & $\mathrm{CH}_{3}$ ops $(90)$ \\
\hline 8 & - & 1831(vs) & 1665 & 1599 & 301.27 & 40.34 & 1651 & 1585 & 212.01 & 63.50 & $\mathrm{CH}_{3}$ ipr (89) \\
\hline 9 & $1762(w)$ & - & 1633 & 1568 & 53.07 & 47.06 & 1619 & 1554 & 54.98 & 60.09 & $\nu \mathrm{CC}(88)$ \\
\hline 10 & 1642(vs) & - & 1608 & 1544 & 33.53 & 10.51 & 1594 & 1530 & 22.89 & 15.20 & vCC (89) \\
\hline 11 & - & $1577(\mathrm{~ms})$ & 1540 & 1478 & 219.91 & 2.37 & 1535 & 1474 & 189.76 & 4.83 & $\nu \mathrm{CC}(85)$ \\
\hline 12 & 1470(s) & - & 1522 & 1461 & 10.98 & 8.29 & 1517 & 1456 & 12.55 & 9.11 & vCC (86) \\
\hline 13 & - & $1468(\mathrm{~ms})$ & 1512 & 1451 & 7.47 & 5.48 & 1503 & 1443 & 34.12 & 4.13 & $\vee \operatorname{CC}(85)$ \\
\hline 14 & $1418(\mathrm{~ms})$ & - & 1447 & 1389 & 81.58 & 0.42 & 1436 & 1379 & 72.96 & 0.35 & vCC (87) \\
\hline 15 & - & $1410(\mathrm{~s})$ & 1427 & 1370 & 27.96 & 1.76 & 1424 & 1367 & 51.77 & 1.74 & $v \mathrm{CC}(84)$ \\
\hline 16 & $1356(\mathrm{~ms})$ & - & 1379 & 1324 & 13.56 & 1.26 & 1356 & 1301 & 3.96 & 13.26 & vCC (82) \\
\hline 17 & - & $1349(\mathrm{~s})$ & 1334 & 1281 & 76.70 & 33.93 & 1327 & 1274 & 10.09 & 13.15 & $v \mathrm{CO}(80)$ \\
\hline 18 & $1318(\mathrm{~s})$ & - & 1284 & 1233 & 267.53 & 14.58 & 1277 & 1225 & 254.65 & 5.89 & $\vee \operatorname{CO}(81)$ \\
\hline 19 & - & $1307(\mathrm{~ms})$ & 1252 & 1202 & 18.93 & 1.56 & 1242 & 1193 & 83.82 & 28.07 & b OH (78) \\
\hline 20 & $1289(\mathrm{~ms})$ & - & 1180 & 1133 & 33.07 & 6.14 & 1170 & 1123 & 131.90 & 7.81 & $\mathrm{CH}_{3} \mathrm{ipb}(79)$ \\
\hline 21 & - & $1286(\mathrm{~s})$ & 1140 & 1094 & 66.95 & 3.42 & 1133 & 1088 & 2.64 & 7.97 & $\mathrm{CH}_{3} \mathrm{sb}(76)$ \\
\hline 22 & - & $1239(\mathrm{~ms})$ & 1115 & 1071 & 22.04 & 9.05 & 1105 & 1061 & 8.28 & 21.14 & b CH (75) \\
\hline 23 & - & $1213(\mathrm{~s})$ & 1097 & 1053 & 13.22 & 4.74 & 1091 & 1047 & 2.55 & 4.25 & b CH (74) \\
\hline 24 & $1208(\mathrm{~s})$ & - & 1081 & 1037 & 7.33 & 1.22 & 1074 & 1031 & 0.82 & 0.20 & b CH (72) \\
\hline 25 & - & $1140(\mathrm{~s})$ & 1015 & 974 & 1.73 & 0.33 & 1003 & 963 & 2.08 & 0.07 & $\mathrm{CH}_{3}$ opb (68) \\
\hline 26 & - & $1097(\mathrm{~ms})$ & 993 & 953 & 10.93 & 10.90 & 987 & 948 & 18.19 & 15.86 & $\mathrm{CH}_{3}$ opr (67) \\
\hline 27 & - & 1070(s) & 982 & 943 & 12.65 & 0.12 & 958 & 919 & 11.75 & 0.13 & $\mathrm{R}$ asymd (70) \\
\hline 28 & 1024(w) & - & 870 & 835 & 40.06 & 0.56 & 867 & 832 & 5.14 & 11.87 & $\mathrm{R}$ asymd (71) \\
\hline 29 & - & $966(w)$ & 870 & 835 & 7.41 & 13.56 & 866 & 831 & 29.39 & 0.25 & $\omega \mathrm{CC}(65)$ \\
\hline 30 & $963(w)$ & - & 751 & 721 & 4.62 & 1.48 & 733 & 703 & 22.37 & 13.22 & $\omega \mathrm{CC}(64)$ \\
\hline 31 & $938(\mathrm{~s})$ & - & 734 & 705 & 17.86 & 10.56 & 730 & 701 & 0.03 & 0.33 & $\mathrm{R}$ trigd (69) \\
\hline 32 & $881(\mathrm{~s})$ & - & 662 & 636 & 50.12 & 4.17 & 659 & 633 & 34.00 & 4.15 & $\omega \mathrm{OH}(63)$ \\
\hline 33 & - & $859(w)$ & 644 & 618 & 7.59 & 1.21 & 628 & 603 & 0.06 & 0.69 & b CC (70) \\
\hline 34 & 791(s) & - & 598 & 574 & 35.21 & 3.19 & 596 & 572 & 38.34 & 2.48 & b CC (68) \\
\hline 35 & - & $748(\mathrm{~s})$ & 562 & 539 & 24.60 & 0.89 & 559 & 537 & 9.72 & 2.53 & $v \mathrm{CCl}(69)$ \\
\hline 36 & $746(w)$ & - & 548 & 526 & 14.82 & 1.28 & 542 & 521 & 13.16 & 0.17 & b CO (70) \\
\hline 37 & - & $654(w)$ & 443 & 425 & 0.14 & 0.19 & 439 & 421 & 0.29 & 0.03 & b CO (67) \\
\hline 38 & - & $650(w)$ & 390 & 375 & 2.95 & 8.85 & 389 & 373 & 2.40 & 7.83 & t R symd (63) \\
\hline 39 & - & 648(vw) & 378 & 363 & 1.72 & 2.34 & 376 & 361 & 0.74 & 3.95 & t $\mathrm{R}$ trigd (60) \\
\hline 40 & 644(ms) & - & 357 & 343 & 0.95 & 2.94 & 346 & 332 & 3.21 & 4.38 & t R symd (62) \\
\hline 41 & $640(\mathrm{~ms})$ & - & 340 & 326 & 1.85 & 1.68 & 337 & 324 & 5.13 & 0.43 & $\omega \mathrm{CH}(61)$ \\
\hline 42 & $512(w)$ & - & 325 & 312 & 17.95 & 0.77 & 294 & 282 & 25.43 & 0.53 & $\omega \mathrm{CH}(60)$ \\
\hline 43 & - & 498(ms) & 297 & 285 & 18.81 & 0.68 & 281 & 270 & 2.66 & 0.82 & $\omega \mathrm{CH}(58)$ \\
\hline 44 & $436(\mathrm{vw})$ & $436(\mathrm{~s})$ & 248 & 238 & 68.30 & 0.70 & 172 & 165 & 48.08 & 0.83 & b CCl (65) \\
\hline 45 & - & $378(w)$ & 172 & 165 & 8.36 & 1.37 & 167 & 161 & 0.80 & 2.08 & $\omega \operatorname{CO}(56)$ \\
\hline 46 & - & $337(\mathrm{vw})$ & 148 & 142 & 10.95 & 0.83 & 126 & 121 & 5.74 & 0.35 & $\omega \mathrm{CO}(55)$ \\
\hline 47 & - & $185(w)$ & 102 & 97 & 8.79 & 1.42 & 54 & 52 & 6.49 & 1.53 & $\omega \mathrm{CC}(54)$ \\
\hline 48 & - & $170(\mathrm{~ms})$ & 11 & 10 & 3.92 & 0.33 & 11 & 11 & 1.17 & 0.17 & $\mathrm{tCH}_{3}(51)$ \\
\hline $\begin{array}{l}\text { The } \\
\text { iolecul }\end{array}$ & $\begin{array}{l}\text { easiest } \\
\mathrm{e} \text { is too }\end{array}$ & $\begin{array}{l}\text { ay to con } \\
\text { recise for }\end{array}$ & $\begin{array}{l}\mathrm{m} \text { bon } \\
\mathrm{O}-\mathrm{H}\end{array}$ & $\begin{array}{l}\text { ding } s t \\
\text { band } 1\end{array}$ & $\begin{array}{l}\text { trength } \\
\text { position. }\end{array}$ & $\begin{array}{l}\text { any } \\
\text { eaks }\end{array}$ & \multicolumn{3}{|c|}{$\begin{array}{l}\text { stretched in the region of } \\
3500-3600 \mathrm{~cm}^{-1} \text { are strong } \\
\text { enough to confirm } \\
\text { intermolecular hydrogen }\end{array}$} & & \\
\hline \multicolumn{6}{|c|}{$\begin{array}{l}\text { Retrieval Number: D10431284S419/2019@BEIESP } \\
\text { DOI:10.35940/ijrte.D1043.1284S419 }\end{array}$} & \multicolumn{5}{|c|}{$\begin{array}{l}\text { Published By: } \\
\text { Blue Eyes Intelligence Engineering } \\
\text { \& Sciences Publication }\end{array}$} & \\
\hline
\end{tabular}


bonding system [13]. The vibration peak at $3544 \mathrm{~cm}-1$ confirms CHAP strong absorption due to stretching of $\mathrm{O}-\mathrm{H}$ bond. The unity confirmation and overall results of molecule was well supported by TED. Table III illustrates vibrations of hydroxyl groups present in plane and out-of plane.

\section{C-H Vibrations}

CHAP molecule also consists of $\mathrm{C}-\mathrm{H}$ vibration due to presence of aromatic compounds. In the present work, stretching band at $3080 \mathrm{~cm}^{-1}$ present in infrared and bands at $3075,3011 \mathrm{~cm}^{-1}$ from the Fourier Raman confirms C-H stretching vibration and agreed well with the literature [14]. Table III illustrates the in-plane and out-of-plane bending vibrations of $\mathrm{C}-\mathrm{H}$ group and they are found to be in good agreement with the calculated results.

\section{$\mathrm{CH}_{3}$ Vibrations}

A $\mathrm{CH}_{3}$ group frequencies assignment consists of nine fundamental vibrations. The first three vibrations responsible for stretching, while the bending vibration of molecule decided by another three frequencies. The methyl group movement was decided by two rocking modes and single torsional mode.In case of title compound, at $2862 \mathrm{~cm}^{-1}, \mathrm{CH}_{3}$ symmetric stretch frequency is observed in Raman and in-plane $\mathrm{CH}_{3}$ stretch frequencies observed at $2927 \mathrm{~cm}^{-1}$ in both IR and Raman spectra. The mentioned frequency numbers well matched with literature report [15] and TED results. Raman studies are enough to find out the complete vibrational in-plane and out of plane modes. In case of CHAP, the FT-Raman bands obtained at 1831 and $1097 \mathrm{~cm}^{-1}$ are assigned to $\mathrm{CH}_{3}$ in-plane and out-of-plane rocking modes, similarly the bands at $2913 \mathrm{~cm}^{-1}$ in IR and $1140 \mathrm{~cm}^{-1}$ in Raman credited to $\mathrm{CH}_{3}$ out-of-plane stretching and out-of-plane bending modes, respectively. Also, the band at $170 \mathrm{~cm}^{-1}$ attributed to methyl twisting mode.

\section{$\mathrm{C}=\mathbf{O V i b r a t i o n s}$}

In the FTIR spectrum, the vibration due to carbon and oxygen results into carbonyl bonds. They are most characteristic bands [16] occur in the region $1800-1700 \mathrm{~cm}^{-1}$. The wave numbers at 1318 and $1349 \mathrm{~cm}^{-1}$ in the FTIR and FT-Raman spectra, respectively, are assigned as $\mathrm{C}=\mathrm{O}$ stretching vibrations of CHAP.

\section{C-Cl Vibrations}

The vibrations of the halogen atoms are worth to discuss here, since mixing of vibrations are possible due to the lowering of the molecular symmetry [17]. The Raman band at $748 \mathrm{~cm}^{-1}$ has been assigned to $\mathrm{C}-\mathrm{Cl}$ stretching mode. The $\mathrm{C}-\mathrm{Cl}$ in-plane bending and out-of-plane bending vibrations are also summarized in the Table III.

\section{C-C Vibrations}

The bands between $1400-1650 \mathrm{~cm}^{-1}$ in the aromatic and hetero aromatic compounds are assigned to $\mathrm{C}-\mathrm{C}$ stretching vibrations [18]. The benzene ring modes predominantly involve $\mathrm{C}-\mathrm{C}$ bonds. The vibrational frequencies at 1762 , $1642,1470,1418,1356 \mathrm{~cm}^{-1}$ in IR and $1577,1468,1410 \mathrm{~cm}^{-1}$ in Raman are associated with $\mathrm{C}-\mathrm{C}$ stretching modes of carbon skeleton. The ring out-of-plane and in-plane bending modes have also been identified in the Table III. All these vibrations are in excellent concurrence with the computed values.

\section{Mulliken Charges Analysis}

Charge distributions plays significant role in the calculation of quantum mechanical molecular systems [19].
The electron distributions in CHAP were carried out for the comparison of different choice of the basis sets using Mulliken population analysis. Table IV shows the calculation of Mullikan charge distribution at different basis sets. Electron density rearrangements occur at carbon atom C2 (attached to $\mathrm{OH}$ group) due to high negative charge. Similarly, the redistribution occurs at atoms C3 and C5 having positive charges due to the attachment of $\mathrm{CO}-\mathrm{CH} 3$ and $\mathrm{Cl}$ groups, respectively. A net positive charge is surrounded to hydrogen atom because they are electron acceptors.

\section{HOMO-LUMO Analysis}

The electrical and optical properties are responsible for chemical reaction in the molecule. The molecular orbital arrangements such as highest occupied molecular orbital (HOMO) and lowest unoccupied molecular orbital (LUMO) directly involves in chemical reaction [20] due to overlapping in CHAP. The HOMO-LUMO orbital for CHAP is shown in Fig. 3.In this study, the HOMO is located over ring system, chlorine and oxygen atoms and LUMO: of $\pi$ nature, (i.e. benzene ring) is delocalized over the whole $\mathrm{C}-\mathrm{C}$ bond; as a result the $\mathrm{HOMO} \rightarrow$ LUMO transition implies an electron density transfer to the $\mathrm{C}-\mathrm{C}$ bond of the benzene ring and $\mathrm{CO}-\mathrm{CH}_{3}$ group from chlorine atom. The HOMO-LUMO energy gap is found to be $4.501 \mathrm{eV}$ by B3LYP/6-311++G(d,p) method. This explains the ultimate charge transfer interaction within the molecule, which influences the biological activity of the molecule.

Table IV.Mulliken charges analysis for 5-chloro-2-hydroxy acetophenone

\begin{tabular}{ccc}
\hline & \multicolumn{2}{c}{ Atomic charges (Mulliken) } \\
\cline { 2 - 3 } Atoms & B3LYP/6-31+G(d,p) & B3LYP/6-311++G(d,p) \\
\cline { 2 - 3 } C1 & -0.3403 & -0.5451 \\
C2 & -1.1625 & -1.4285 \\
C3 & 1.4382 & 1.3485 \\
C4 & -1.5897 & -1.0586 \\
C5 & 0.9714 & 0.9027 \\
C6 & -0.6300 & -0.3865 \\
O7 & -0.6046 & -0.4873 \\
H8 & 0.4427 & 0.4248 \\
C9 & 0.4770 & 0.0506 \\
O10 & -0.4178 & -0.3351 \\
C11 & -0.9938 & -1.1044 \\
H12 & 0.2529 & 0.3420 \\
H13 & 0.2209 & 0.2650 \\
H14 & 0.2209 & 0.2649 \\
H15 & 0.2535 & 0.3680 \\
C116 & 0.3640 & 0.7515 \\
H17 & 0.2117 & 0.3039 \\
H18 & 0.2047 & 0.3234 \\
\hline
\end{tabular}




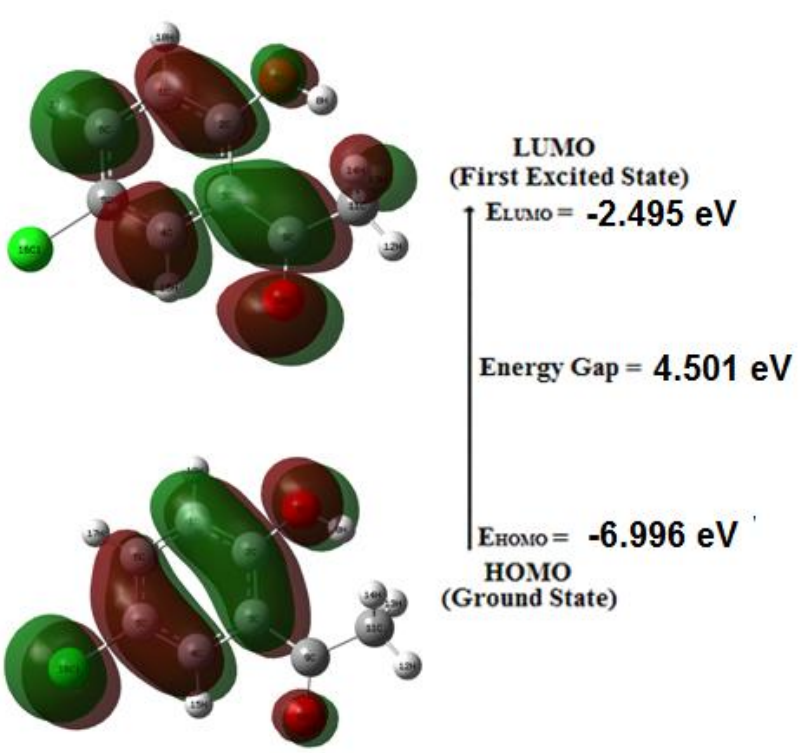

Figure 3. HOMO-LUMO of 5-chloro-2-hydroxy acetophenone

\section{CONCLUSION}

The vibrational fundamental frequencies of 5-chloro-2-hydroxy acetophenone have been investigated with DFT-B3LYP through 6-31+G(d,p) and 6-311++G(d,p) level calculations. Various parameters such as stabled geometries and frequencies of CHAP were confirmed by FTIR and FT-Raman spectroscopies on the basis of $\mathrm{C} 1$ point group symmetry. The frequency assignment for normal modes is supported by the TED calculation. The perceptive of CHAP chemical activity and properties might be confirmed through smaller HOMO-LUMO band gap. In addition, the thermodynamic properties and results of Mulliken's charge of CHAP have been designed and discussed. These outcomes will be of support in the quest of the experimental and theoretical evidence for 5-chloro-2-hydroxy acetophenone in reaction intermediaries, pharmaceuticals and agrochemicals industries.

\section{REFERENCES}

1. X. Zhang, L. Shan, H. Huang, X. Yang, X. Liang, A. Xing, H. Huang, X. Liu, J. Su, and W. Zhang, "Rapid identification of acetophenones in two Cynanchum species using liquid chromatography-electrospray ionization tandem mass spectrometry," J. Pharm. Biomed. Anal., vol. 49, pp. 715-725, 2009.

2. Y.R. Prasad, A.S. Rao, and R. Rambabu, "Synthesis of some 4'-amino chalcones and their antiinflammatory and antimicrobial activity," Asian J. Chem., vol. 21, pp. 907-914, 2009.

3. P.M. Sivakumar, G. Sheshayan, and M. Doble, "Experimental and QSAR of Acetophenones as Antibacterial Agents," Chem. Biol. Drug Des. vol. 72, pp. 303-313, 2008.

4. S.K. Seth, D.K. Hazra, Monika Mukherjee, and Tanusree Kar, "Synthesis, structural elucidation and DFT studies of ortho-hydroxy acetophenones," J. Mol. Struct. vol. 936, pp. 277-282, 2009.

5. P. Anbarasu, and M. Arivazhagan, "Scaled quantum chemical study of structure and vibrational spectra of 5-fluro-2-hydroxyacetophenone," Indian. J. Pure and Appl. Phys, vol. 49, pp. 227-233, 2011.

6. I. Cıkla, Ş. Güveli, M. Yavuz, and T.B. Demirci, B. Ülküseven, "5-Methyl-2-hydroxy-acetophenone-thiosemicarbazone and its nickel(II) complex: Crystallographic, spectroscopic (IR, NMR and UV) and DFT studies," Polyhedron, vol. 105, pp. 104-114, 2016.

7. H.J. Frisch, G.W. Trucks, H.B. Schlegel, G.E. Scuseria, M.A. Robb, J.R. Cheeseman, H.Nakatsuji, M. Caricato, X. Li, H.P. Hratchian, K. Toyota, R. Fukuda, J.Hasegawa, M. Ishida, R. Nakajima, Y. Honda, O. Kilao, H. Nakai, T. Verven, J. A. Montgomery Jr., J.E. Peralta, F. Ogliaro, M. Bearpark, J. J. Heyd, E. Brothers, K. N. Kudin, V.N. Staroveror, R. Kobayashi, J. Normand, K. Ragavachari, A. Rendell,
J.C. Burant, S. J. Tomasi, M. Cossi, N. Rega, J. M. Millam, M. Klene, J. E. Knox, J. B. Cross, V. Bakken, C. Adamo, J. Jaramillo, R. Gomperts, R.E. Strattmann, O. Yazyev, A.J. Austin, R. Cammi, J.W. Ochetrski, R.L. Martin, K. Morokuma, V.G. Zakrazawski, G.A.Votn, P. Salvador, J.J. Dannenberg, S. Dapprich, A.D. Daniels, O. Farkas and J.B. Foresman, Gaussian O.G., Revision A.O2, Gaussian Inc., Wallingford, CT. 2009.

8. A.D. Becke, "Density-functional thermochemistry. III. The role of exact exchange," J. Chem. Phys., vol. 98, pp. 5648-5652, 1993.

9. C. Lee, W. Yang, and R.R. Parr, "Development of the Colic-Salvetti correlation-energy formula into a functional of the electron density," Phys. Rev. B., vol.37, pp. 785-789, 1988.

10. MOLVIB (V.7.0): Calculation of Harmonic Force Fields and Vibrational Modes of Molecules, QCPE Program No. 807, 2002.

11. A. Filarowski, A. Koll, A. Kochel, J. Kalenik, and P.E. Hansen, "The intramolecular hydrogen bond in ortho-hydroxy acetophenones," J. Mol. Struct., vol. 700, pp. 67-72, 2004.

12. D.C. Young, Computional Chemistry: A Pratical Guide for Applying Techniques to Real-World Problems, John Wiley \& Sons, Inc., New York, 2001.

13. V. Krishnakmar, R. Mathammal, and R. Muthunatesan, "Structures and vibrational frequencies of 2-naphthoic acid and 6-bromo-2-naphthoic acid based on density functional theory calculations," Spectrochim Acta A Mol Biomol Spectrosc., vol.70, pp. 201-209, 2008.

14. D. Sajan, J. Binoy, I. Hubert Joe, V.S. Jayakumar and J. Zaleski, J. Raman Spectrosc., "Vibrational spectral studies of methyl 3-(4-methoxyphenyl)prop-2-enoate, a new organic non-linear optic crystal," vol. 36, pp. 221-236, 2005.

15. N. Y. SugirthaSuni, L. GuruPrasad, and R. Ganapathi Raman Rajendran, "Vibrational Analysis and Non Linear Optical Activity of 3-fluoro-4-methylbenzonitrile," Orient. J. Chem., vol. 34(3), pp. 1638-1645, 2018.

16. S. Jeyavijayan, "Molecular structure, spectroscopic (FTIR, FT-Raman, $13 \mathrm{C}$ and $1 \mathrm{H}$ NMR, UV), polarizability and first-order hyperpolarizability, HOMO-LUMO analysis of 2,4-difluoroacetophenone," Spectrochim. Acta A Mol. Biomol. Spectrosc., vol. 136, pp. 553-566, 2015.

17. D.M. Chemes, D.J.A. de Armiño, E.H. Cutin, H. Oberhammer and N.L. Robles, "Synthesis, characterization and vibrational studies of p-chlorosulfinylaniline," J. Mol. Struct. vol. 1127, pp. 191-198, 2017.

18. T. Gnanasambandan, S. Gunasekaran, and S. Seshadri, Molecular structure analysis and spectroscopic characterization of carbimazole with experimental (FT-IR, FT-Raman and UV-Vis) techniques and quantum chemical calculations," J. Mol. Struct. vol. 1052, pp. 38-49, 2013.

19. S. Gunasekaran, S. Kumaresan, R. Arunbalaji, G. Anand, and S. Srinivasan, "Density functional theory study of vibrational spectra, and assignment of fundamental modes of dacarbazine," J. Chem. Sci. vol. 120, pp. 315-324, 2008.

20. I. Fleming, Frontier Orbitals and Organic Chemical Reactions, Wiley, London, 1976.

\section{AUTHORS PROFILE}

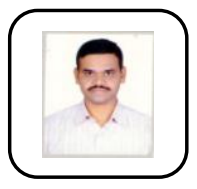

Palani Murugan has completed M.Sc from Bharathiar University, Coimbatore and M.Phil from Bharathidasan University, Tiruchirapalli. Presently working as Lecturer, Physics, in DR.B.R.Ambedkar Institute of Technology Port Blair since June 2012. Currently pursuing Ph.D from Kalasalingam Academy of Research and Education.

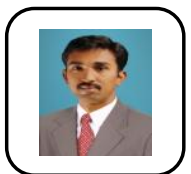

S. Jeyavijayan has completed M.Sc. and Ph.D. from Bharathidasan University, Trichirappalli in 2014 Currently working as Assistant Professor in the Department of Physics, Kalasalingam Academy of Research and Education and published more than 25 papers in National and International Journals. His fields of interest are Molecular Spectroscopy and Theoretical and Computational chemistry.

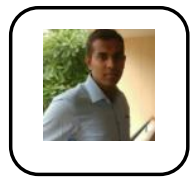

Dr Naidu Dhanpal Jayram is working as Assistant Professor Department of Physics Kalasalingam Academy of Research and Education. His Research interests are thin films and nanomaterials. He has obtained his doctorate degree from Bharathiar University, Coimbatore, 
Tamilnadu. He is recipient of National Postdoctoral fellowship and completed Postdoc from Indian institute of science, Bangalore. He is published 12 papers in international and national journals.

K. Viswanathan has completed M.Sc. and Ph.D. from University of Kerala Trivandrum in 1984 and worked in the High Energy Cosmic Ray group of TIFR for 22 years. Worked as Professor and HoD of Physics in Karpagam University for 10 years. Joined Kalasalingam University in August 2016 as Senior Professor. His fields of interest are molecular spectroscopy and Astroparticle physics at high energies. 